\title{
O PROCESSO DE FORTALECIMENTO DO PODER RÉGIO NO REINADO DE FERNANDO III O SANTO DE CASTELA (1217-1252) E LEÃO (1230-1252) INSERIDO NO CONTEXTO DA RECONQUISTA CRISTÃ IBÉRICA
}

Rafael de Mesquita Diehl Orientação: Fátima Regina Fernandes

PALAVRAS-CHAVE: Fernando III, o Santo; poder régio, Reconquista Cristã Ibérica.

Esta pesquisa propõe-se a analisar o aspecto do fortalecimento e centralização do poder régio durante o reinado de Fernando III, o Santo de Castela (1217-1252) e Leão (1230-1252). Tal aspecto ocorre inserido no processo de Reconquista Cristã na Península Ibérica. Entendemos que as relações da realeza com outros grupos sociais e com outros reinos durante a Reconquista foi um dos fatores que gerou o fortalecimento do poder régio castelhano. Este processo também é acompanhado da construção de uma legitimação teórica, através de crônicas e tratados. Aqui buscaremos observar como algumas crônicas construíram essa legitimação teórica.

O que buscamos aqui é analisar como se dá o processo de fortalecimento do poder régio na prática política e de que maneira ele é construído teoricamente pelas duas crônicas já citadas. Assim poderemos observar como a prática e a teoria se relacionam no dito processo, que é peculiar se comparado com os demais reinos europeus que passaram por processo semelhante de centralização régia por maneiras, contudo, distintas. Para tanto nos concentraremos em analisar as relações do poder régio com os principais agentes políticos do contexto, bem como analisar de forma contextualizada as crônicas, afim observar a produção das ditas fontes relacionadas com os acontecimentos políticos do período que as influenciaram. Em suma, buscar uma análise que entenda a prática da política de expansão territorial e a produção das crônicas dos reis como partes de um mesmo projeto de fortalecimento do poder régio. 
Para nossa pesquisa, utilizaremos como base os referencias teórico-metodológicos de historiadores da Reconquista como Derek Lomax e de estudiosos do gênero cronístico medieval ibérico como Leonardo Funes. Entendemos, como Lomax, que uma história da Península Ibérica nesse período do medievo não pode ser compreendida sem o entendimento do contexto da Reconquista. Também entendemos que as fontes devem ser analisados de forma contextualizada para uma melhor compreensão de seus efeitos históricos.

O contexto ibérico na passagem do século XII para o XIII é caracterizado por certa instabilidade política nos reinos cristãos peninsulares, ao passo de que os espaços muçulmanos ibéricos observam uma unificação em torno do Califado Almôada. Um dos conflitos mais evidentes no lado cristão é a disputa entre Castela e Leão. Tal conflito é motivado pelas disputas de fronteiras, de "eixos de expansão" e também por disputas de jurisdições eclesiásticas. O avanço almôada em direção aos territórios cristãos, contudo gerou uma aliança momentânea entre alguns reinos cristãos peninsulares de Castela, Aragão e Navarra. O enfrentamento entre as hostes cristãs e muçulmanas deu-se na Batalha das Navas de Tolosa em 1212, onde os almôadas sofreram uma derrota significativa. Esta derrota provocou um enfraquecimento do Califado Almôada, ao passo de que surgiram várias taifas, reinos independentes nos territórios muçulmanos ibéricos. ${ }^{1}$

Os anos que antecederam a subida de Fernando III ao trono castelhano em 1217 foram marcados por certa estagnação do processo de Reconquista, haja vista que a corte encontrava-se em uma disputa pela tutela do rei Henrique I que ainda não tinha atingido a maioridade. Não obstante, havia relativa estabilidade política nas relações de Castela com os demais reinos peninsulares. Com a morte prematura de Henrique I em 1217, assume o trono a rainha

\footnotetext{
${ }^{1}$ LOMAX, Derek W.. La Reconquista. Barcelona: Editorial Crítica, 1984, pp. 169175.
} 
Berengária, que concede o trono ao filho, Fernando. ${ }^{2}$ O início do reinado de Fernando III foi conturbado, visto que o dito rei castelhano enfrentou oposição dos condes de Lara, seus vassalos, bem como a de seu pai, o rei Afonso IX de Leão.

Fernando III conseguiu neutralizar a oposição dos condes de Lara rapidamente, mas a oposição de Afonso IX continuou certo tempo até que os nobres e prelados de ambos os reinos conseguiram estabelecer um tratado de paz, com a mediação da Sé Apostólica. Tal tratado obrigava ambas as partes ao auxílio mútuo em caso de guerras contra os mouros. $^{3}$

A relativa estabilidade política obtida em 1224, após derrotar algumas pequenas revoltas nobiliárquicas, permite à Fernando iniciar uma política de expansão territorial em direção aos territórios mouriscos. A partir deste período, a Reconquista constituirá em um dos principais aspectos da política do monarca castelhano. Após algumas vitórias, a ação de re-ocupação territorial foi interrompida pela morte de Afonso IX, em 1230.

A questão sucessória do reino de Leão gerou uma nova situação de instabilidade política, visto que se por um lado Fernando havia sido jurado como herdeiro legítimo da coroa leonesa no seu nascimento, o testamento de Afonso IX declarava como legítimas herdeiras do reino as infantas Sancha e Dulce, filhas de uma outra

\footnotetext{
${ }^{2}$ Fernando era filho de Afonso IX de Leão e de Berengária, filha de Afonso VIII de Castela. Em 1196, devido ao conflitos de Leão com outros reinos cristãos ibéricos, o papa Celetino III ordenou ao arcebispo Martin de Toledo que excomungasse Afonso IX por usar hostes muçulmanas para atacar cristãos, oferecendo indulgências a quem combatesse o rei leonês e liberando os leoneses da obediência a seu rei. Afonso IX dirigiu-se a Sevilha para solicitar auxílio do Califa, mas os reis de Portugal, Castela e Aragão obrigaram o rei leonês a firmar a paz com Castela, mediante o casamento do mesmo com a filha de Afonso VIII, Berengária. Tal casamento, contudo, foi mantido somente até o nascimento de um herdeiro, tendo sido considerado nulo posteriormente pelo papa Inocêncio III, pelo fator de consangüinidade, o que tornava um matrimônio nulo, segundo os cânones eclesiásticos. Para tanto, vide LOMAX, Derek W. Op. cit.. pp.159-160.

${ }^{3}$ LAFUNETE, Modesto. Historia de España. Tomo 4. Barcelona: Montanery y Simon, S. A., 1930, pp. 31-33.
} 
união do falecido monarca. Com sua ida a Leão, Fernando enfrentou a oposição de alguns nobres, mas sua mãe a rainha Berengária conseguiu negociar com as infantas o trono para o filho em troca de uma pensão vitalícia para as duas filhas de Afonso IX. Com o acordo firmado, o monarca castelhano conseguiu ser coroado rei de Leão com o apoio do bispo e o povo da cidade de Leão. ${ }^{4}$

Tendo consolidado seu poder nos dois reinos, Fernando continuou sua política de Reconquista, aproveitando-se da fragmentação política no ambiente muçulmano peninsular. Desta forma, o poder régio castelhano também buscou uma estabilidade com os demais reinos cristãos da Península, firmando tratados resolvendo antigas disputas e definindo os "eixos de expansão" de cada reino. Assim, iniciou-se o período denominando por Derek Lomax de "a grande Reconquista”, em que Castela e Leão sob Fernando III e Aragão sob Jaime I conquistaram praticamente todos os territórios de Al-Andalus, sobrando apenas o reino de Granada no sul, que prestou vassalagem ao rei de Castela. Suas principais conquistas foram Úbeda (1234), Córdoba (1236) - conquista que tinha um grande significado simbólico visto que se tratava da antiga sede do Califado Omíada - Jaén (1246) e Sevilla (1248) - a taifa mais importante no período.

Como se pode notar, apesar dos êxitos de governo, o contexto demonstra que Fernando III subiu ao trono em uma situação de questionamento de sua legitimidade e também de um poder fragilizado, se observarmos as revoltas nobiliárquicas dos primeiros anos. Situação semelhante ocorre quando o dito rei enfrentou a questão sucessória do reino de Leão em 1230. Desta forma, as crônicas régias trabalharam no sentido de construir uma história do reino centralizada na figura do rei, enaltecendo seus feitos e justificando seu poder e legitimidade. Para tanto analisaremos os relatos do reinado de Fernando III contidos na Primera Crónica

${ }^{4}$ LAFUENTE, Modesto. Op. Cit., pp. 33-39; MARTÍN, José-Luis. Alfonso IX y sus relaciones con Castilla. Espacio, Tiempo y Forma. Serie III. Historia Medieval, t. 7, 1994, pp. 22-23. 
General que mando componer Alfonso el Sabio y se continuaba bajo Sancho IV em 1289. ${ }^{5}$ Esta Crônica nos permite observar dois relatos distintos, mas que legitimam ambos o fortalecimento do poder régio castelhano, uma visão ligada ao Episcopado (Arcebispo de Toledo, Rodrigo Jiménez de Rada) e outra ligada à corte de Afonso $\mathrm{X}$ de Castela e Leão (primogênito e herdeiro de Fernando III) e seus sucessores.

A crônica do Arcebispo Rodrigo, encomendada pelo próprio Fernando III buscava criar uma legitimidade às conquistas do rei castelhano, criando uma idéia de unidade peninsular (tendo em vista que o território dominado por Fernando III era composto por vários reinos distintos) em torno do povo visigodo, do qual os povos peninsulares seriam descendentes na ótica do arcebispo. Contudo, ao criar a unidade em torno dos visigodos, Rodrigo coloca a unidade em torno da realeza, visto que os visigodos constituíam a minoria politizada na antiguidade tardia, como salienta Lomax. Grande parte dos relatos de Fernando III contidos na Primera Crónica General são simplesmente transcrições da Crônica do Toledano. ${ }^{6}$

Já a Primera Crónica General, nos seus relatos próprios, enfatiza mais a figura do monarca, procurando apresentar a história do reino como uma sucessão de senhorios, uma seqüência de reis. Neste caso, os reis são descritos como os grandes protagonistas da história. ${ }^{7}$ Segundo Jenaro-Costas, isso também demonstra o objetivo de Afonso X enaltecer a figura deu seu pai e antecessor como uma

\footnotetext{
${ }^{5}$ Primera Crónica General que mando componer Alfonso el Sabio y se continuaba bajo Sancho IV em 1289. Edição de MENÉNDEZ-PIDAL, Ramón. Madrid: Editorial Gredos, 1955.

${ }^{6}$ LOMAX, Derek W.. Rodrigo Jiménez de Rada como Historiador. In: AHI, Actas $V$, Centro Virtual Cervantes, 1974, pp. 588-589.

7 FERNÁNDEZ-ORDOÑÉZ, Inês. Las Estórias de Alfonso el Sabio. Madrid: Istmo, 1992, p. 38 apud FUNES, Leonardo. Um Nuevo avance e el conocimiento de la Historiografia Alfonsí. In: INCIPIT. Volume XII, Buenos Aires: Seminario de Edición y Crítica textual, 1992, p. 211.
} 
estratégia de construção de sua própria legitimidade e consolidação de seu poder. ${ }^{8}$

Dessa forma, observamos como o processo de centralização do poder régio no reinado de Fernando III foi resultado de um conjunto de estratégias de relações com os grupos políticos e sóciais importantes do reino e do âmbito externo.

No âmbito interno, o rei consolidou seu poder sobre a nobreza guerreira utilizando-se das guerras de conquista, que ao mesmo tempo em que beneficiavam a nobreza com a concessão de terras, senhorios, títulos e privilégios, também afirmavam o poder do rei que comandava as expedições e que concedia os privilégios entre os nobres. O rei também fortaleceu seu poder na medida em que se mantinha estritamente ligado com o arcebispado de Toledo e com grande parte do episcopado. A afirmação do poder régio em âmbito interno firma-se também com a concessão de fueros às cidades, sendo que assim o rei estabelecia um vínculo direto com o meio citadino, sem a intermediação dos nobres. Como podemos observar, a idéia de unidade presente nas crônicas está relacionada com a prática dessa política que visa através de alianças com os grupos sociais influentes ou detentores de poder centralizar o poder político na pessoa do rei.

No âmbito externo, ao incorporar o reino de Leão, o rei castelhano eliminava, de certa forma, seu principal rival político no ambiente ibérico dos reinos cristãos. Ao fazer tratados com Portugal e Aragão, conseguiu obter uma estabilidade. Esta estabilidade também foi reforçada através de alianças matrimoniais com casas nobiliárquicas e régias de outros reinos europeus fora do ambiente peninsular. Por fim, ao investir no projeto de Reconquista, o rei contribuiu com o Papado ao promover a expansão da Cristandade.

$\mathrm{O}$ rei Fernando III construiu o fortalecimento de seu poder pessoal alicerçado nos poderes do reino, o Episcopado, as Ordens religiosas, e a Nobreza. Aliado a isso, buscou construir uma

8 COSTAS RODRÍGUEZ, Jenaro. Fernando III a través de las Crónicas Medievales. Zamora: Exmo. Ayuntamiento de Zamora y Centro de la UNED de Zamora, 2001, p. 26. 
legitimidade teórica. As crônicas oficiais de seu reinado e do reinado posterior criaram uma idéia de unidade e estabilidade em torno da figura do monarca, mostrando o rei como o protagonista da história do reino e como um fato aglutinador dos diversos poderes e grupos sociais de seus domínios. 